\title{
PATTERN REVERSAL VISUAL EVOKED POTENTIALS IN MIGRAINE SUBJECTS WITHOUT AURA
}

\author{
PEDRO F. MOREIRA FILHO*, ADALMIR M. DANTAS*
}

\begin{abstract}
SUMMARY - Twenty seven patients with migraine without aura were investigated. The age was between 12 and 54 years; 5 were men and 22 women. The diagnosis of migraine was made according to the classification proposed by the International Headache Society. The method of visual evoked potential was performed with pattern reversal (VEP-PR), with monocular stimulation. The stimulation was performed with pattern reversal with $4 \times 4 \mathrm{~cm}$ black and white and red and green squared screen placed 1 meter from the nasion at stimulus frequency $1 / s ; 128$ individual trials were analysed. The VEP-PR with black/white and red/green study showed a significant increase of value of the P-100 latency in 10 migraine patients. In 8 cases the LP100 in VEP-PR black/white was normal but in VEP-PR red/green the LP100 showed increase. Specifically in 1 of our cases, LP100 were normal in VEP-PR black/white but in the red/green there were no reproductice waves. On basis of these observations we consider that the method of VEP-PR is an useful instrument for investigation of migraine patients without aura.
\end{abstract}

KEY WORDS: migraine, pattern reversal evoked potential.

\section{Potencial evocado visual por padrão reverso em pacientes com enxaqueca sem aura}

RESUMO - Foram submetidos a estudo por potencial evocado visual padrão reverso (PEV-PR), preto e branco e vermelho e verde, 27 pacientes com o diagnóstico de enxaqueca sem aura pelos critérios estabelecidos pela Sociedade Internacional de Cefaléia. O estímulo usado em nossos enfermos foi o estruturado produzido por aparelho de televisão de 20 polegadas. Utilizamos inicialmente o padrão reverso xadrez em preto e branco e a seguir o vermelho e verde. A frequência foi de 1 estímulo por segundo e o total de estímulos somados foi 128. Constatamos latências normais da onda P100 em 9 casos tanto no PEV-PR preto/branco quanto no vermelho/ verde. As latências da onda P100 estavam aumentadas em 10 casos tanto no PEV-PR preto/branco como no vermelho/verde. Em 8 casos nos quais as latências de onda P100 estavam normais no PEV-PR preto/branco, havia comprometimento na PEV-PR vermelho/verde . Em 1 dos nossos casos a latência da onda P100 estava normal no PEV-PR preto/branco; entretanto no vermelho/verde não se evidenciaram ondas P-100. Será necessário maior número de exames para que no futuro possamos obter dados que nos ajudem a melhor entender a fisiopatologia da enxaqueca.

PALAVRAS-CHAVE: enxaqueca, migrânea, potencial evocado visual padrão reverso.

The functional exploration of the visual system involving migraine patients through the method of visual evoked potential (VEP) was suggested in 1966 by Richey et al. ${ }^{14}$ and special attention has been given to it by many researchers, especially in the recent years. The majority of these researches using as means of stimulation the flash (VEP-F) has not allowed comparison of results, due to the great variation of the methods used. Few recent investigations have used the VEP-PR for stimulation. The advantage of the VEP-PR upon the VEP-F is to obtain greater precision in the individual

*Departament of Clinical Medicine (Neurology), Hospital Universitário Antônio Pedro, Universidade Federal Fluminense, Rio de Janeiro. Aceite: 1-junho-1994.

Dr. Pedro Ferreira Moreira Filho - Av. N.Sra. de Copacabana 540/606 - 22.020-000 Rio de Janeiro RJ - Brasil. 
answers and less latency dispersion in the control groups consequently providing more accurate data.

This study was carried out for evaluating the optical system in migraine patients without aura through the measuring of P100 wave PEV-PR latency, in the attempt of obtaining data which might help in understanding the pathophysiology of this affection.

\section{METHODS}

Twenty seven migraine without aura patients diagnosed through the criteria established by the International Headache Society' were submitted to the VEP-PR black and white, and red and green. Twenty two were women and 5 were men. The age group varied from 12 to 54 years. The patients presented migraine headache symptomatology for 1 to 24 years.

All patients had normal neurological examination. They were evaluated ophthalmologically and those who needed corrective lenses only did the VEP-PR after that correction. The patients who used prophylactic medication for migraine headache were oriented to stop taking the drug at last 7 days before the exam (VEPPR). The use of analgesic, derived from ergatomine and benzodiazepines, was only permitted until 72 hours before the exam.

The P100 wave latency were measured in VEP-PR black and white and in VEP-PR red and green (Table 1), as well as the amplitudes (Table 2).

The stimulus used in the 27 patients was the structured or the one with geometric nature produced by a 20 inches television set. The reversal pattern in black and white was initially used followed by the reversal pattern in red and green. The $4 \times 4 \mathrm{~cm}$ squares used with stimulators correspond to a visual angle of about $30^{\circ}$, forming a checkers-board. The stimulus were inverted, that is black and white reversal pattern followed by the red and green one alternated in the same place in the screen, respectivelly, with the luminance staying constant. The frequency was 1 second intervals and the total of stimulus was 128.

Three electrodes were used to obtain the VEP-PR. The active electrode was placed $2 \mathrm{~cm}$ above the external occipital protuberance, the reference electrode in the vertex and the earth eletrode in the forehead.

The exam was performed in a quiet room place. The patient was sat 1 meter from the televison set. The stimulus was monocular. Initially the left eye was covered by a band and the right eye's trajectory was registered. Afterwards, the same proccess was repeated with the other eye. This proccess was done in the VEP-PR black and white, and red and green.

\section{RESULTS}

The results are summarized in Tables 1 and 2 .

Normal P100 wave latencies were observed both in the VEP-PR black and white and red and green in 9 cases ( 8 women and 1 men).

The P100 wave latency in the VEP-PR black and white and red and green were increased in 10 cases (8 women and 2 men).

In 8 cases in which the P100 wave latency in VEP-PR black and white were normal there was compromising in VEP-PR red and green ( 6 women and 2 men). Specifically, in 1 of our cases the P100 wave latency was normal in the VEP-PR black and white, but in the red and green there were no reproductive waves.

\section{COMMENTS}

Golla and Winter ${ }^{4}$, examined 113 episodical headache patients with aura, vomit and visual disturbances or paresthesias. The patients were submitted to the VEP with stroboscopic stimulus with a 3 to 25 flashes per second frequency during 2 minutes. The source of light was placed about $5 \mathrm{~cm}$ of the patient's nasion in a way that all of the visual field was stimulated. The results showed a sensible difference in the responses among the 113 migraine sufferers and the 50 individuals from the control group: (a) in the control group the alpha rhythm, after reaching its maximum peak, 
Table 1. P100 wave latency ( $\mathrm{ms}$ ) in 27 migraine headache without aura patients.

\begin{tabular}{|c|c|c|c|c|}
\hline \multirow[t]{2}{*}{ Patient } & \multicolumn{2}{|c|}{$\begin{array}{c}\text { Reverse } \\
\text { Pattern B\&W }\end{array}$} & \multicolumn{2}{|c|}{$\begin{array}{c}\text { Reverse } \\
\text { Pattern R\&G }\end{array}$} \\
\hline & RE & LE & RE & LE \\
\hline 1 & 115 & 115 & 135 & 135 \\
\hline 2 & 100 & 100 & 100 & 103 \\
\hline 3 & 108 & 108 & 104 & 104 \\
\hline 4 & 100 & 100 & 100 & 100 \\
\hline 5 & 100 & 100 & 105 & 105 \\
\hline 6 & 98 & 100 & 98 & 97 \\
\hline 7 & 112 & 110 & 120 & 125 \\
\hline 8 & 132 & 126 & 130 & 132 \\
\hline 9 & 100 & 100 & 100 & 109 \\
\hline 10 & 120 & 123 & 120 & 123 \\
\hline 11 & 112 & 112 & 120 & 145 \\
\hline 12 & 120 & 125 & 150 & 150 \\
\hline 13 & 125 & 120 & 125 & 120 \\
\hline 14 & 100 & 103 & 104 & 104 \\
\hline 15 & 123 & 123 & 126 & 124 \\
\hline 16 & 108 & 102 & 108 & 104 \\
\hline 17 & 100 & 90 & 128 & 127 \\
\hline 18 & 126 & 125 & 124 & 125 \\
\hline 19 & 114 & 108 & WRW & WRW \\
\hline 20 & 122 & 122 & 122 & 122 \\
\hline 21 & 134 & 134 & 136 & 134 \\
\hline 22 & 127 & 127 & 127 & 127 \\
\hline 23 & 96 & 96 & 100 & 104 \\
\hline 24 & 125 & 118 & 125 & 130 \\
\hline 25 & 100 & 100 & 150 & 150 \\
\hline 26 & 112 & 113 & 125 & 125 \\
\hline 27 & 100 & 103 & 125 & 125 \\
\hline
\end{tabular}

$\mathrm{RE}$, right eye; $\mathrm{LE}$, left eye; $\mathrm{B} \& W$, black/white; R\&G, red/green; ms, miliseconds; WRW, without reproductive waves.
Table 2. P100 wave amplitude $(\mu \mathrm{V})$ in 27 migraine headache without aura patients.

\begin{tabular}{ccccc}
\hline \multirow{2}{*}{ Patient } & \multicolumn{2}{c}{ Reverse } & \multicolumn{2}{c}{ Reverse } \\
& Pattern B\&W & \multicolumn{2}{c}{ Pattern R\&G } \\
& RE & LE & RE & LE \\
\hline \hline 1 & 24 & 26 & 26 & 30 \\
2 & 14 & 20 & 16 & 16 \\
3 & 20 & 20 & 14 & 16 \\
4 & 12 & 12 & 10 & 12 \\
5 & 14 & 10 & 14 & 18 \\
6 & 16 & 16 & 14 & 14 \\
7 & 20 & 26 & 24 & 22 \\
8 & 18 & 18 & 20 & 26 \\
9 & 18 & 18 & 20 & 26 \\
10 & 40 & 40 & 38 & 34 \\
11 & 24 & 20 & 24 & 30 \\
12 & 24 & 20 & 24 & 30 \\
13 & 30 & 30 & 20 & 20 \\
14 & 20 & 14 & 20 & 18 \\
15 & 38 & 38 & 38 & 38 \\
16 & 20 & 30 & 10 & 18 \\
17 & 26 & 18 & 24 & 24 \\
18 & 44 & 44 & 40 & 40 \\
19 & 14 & 14 & WRW & WRW \\
20 & 24 & 26 & 24 & 26 \\
21 & 28 & 32 & 34 & 28 \\
22 & 20 & 16 & 12 & 10 \\
23 & 26 & 30 & 24 & 16 \\
24 & 26 & 30 & 30 & 32 \\
25 & 20 & 20 & 30 & 30 \\
26 & 46 & 46 & 20 & 12 \\
27 & 30 & 30 & 40 & 44 \\
\hline
\end{tabular}

$\mu \mathrm{V}$, microvolts; RE, right eye; LE, left eye; B\&W, black/white; R\&G, red/green; WRW, without reproductive waves.

declines rapidly when the stimulus frequency was greater than 14 flashes/second; this answer was named "N"; (b) in the patients with headache there was a flattening kept at the top of the wave when the frequency was above 20 flashes/second; this answer was named answer " $\mathrm{H}$ ".

Richey et al. ${ }^{14}$ compared the answer of the VEP-F in the central occipital areas in 50 patients with migraine ( 29 without aura and 21 with aura) out of algic period, and in 46 individuals from the control group. The results suggested that the migraine might be associated to the alteration of brain answer to the visual stimulus. The amplitude average was decreased in the migraine patients and the latency was increased only in the female migraine sufferers. There was no alteration in the latencies in the control group or in the male migraine sufferers.

Lehtonen ${ }^{7}$ submitted to the VEP 33 patients (19 without aura and 14 with aura), 28 women and 5 men. The electrodes were placed in $\mathrm{O} 2$, according to the international system 10-206. The 
earth electrode was placed in the superior part of the chest. The luminous stimulus was $40 \mathrm{~cm}$ away from the patients' eyes and the VEP was obtained through two kinds of stimulus: (a) flashes with the frequency of 1 to 2 per second, until 100 stimulus were completed; (b) stroboscopic light with the frequency of 10 to 15 per second, ending in 200 stimulus. In the VEP-F through stroboscopic light, the latencies were greater in migraine headaches patients in relation to the control group and in all used frequencies, particularly when 22 flashes/second were used.

Connolly et al. ${ }^{1}$ studied 16 migraine patients (15 women and $1 \mathrm{men}$ ) with and without aura. They were submitted to non-structured VEP through flashes with 6 different luminous intensities in a 10 stimulus per intensity frequency until the total of 360 stimulus. It was observed that there was no compromise of the P100 latencies in relation to the control group; meanwhile, the P100 amplitudes were lower in the migraine sufferers.

Mariani et al. ${ }^{8}$ using not the VEP-F but the VEP-PR studied 22 patients with migraine without aura (15 women and 7 men ). The television set (Reversal Pattern Stimulator) was placed $1 \mathrm{~m}$ from the patients' nasion, corresponding to a $38^{\circ}$ visual angle, with a frequency of $1 \mathrm{~Hz}$ until completing 128 stimulus. The active electrodes were placed $5 \mathrm{~cm}$ above, and on the side of the inion at the left and at the right and the reference electrode in Fz. The obtained results did not show a significative difference in the latencies and in the P100 amplitude in migraine patients in relation to the control group.

Dalla Volta and Anzola ${ }^{2}$ studied 8 migraine without aura patients (5 women and 3 men) through the VEP obtained through stimulus in the hemifield in binocular vision. The electrodes were placed in $\mathrm{O} 1, \mathrm{Oz}$ and $\mathrm{O} 2$ in accordance to the international nomenclature. Both hemifields were stimulated in two consecutive sections. In each patient the amplitudes and latencies of the two ipsolateral registries of P100 were compared, not being shown any P100 asymmetry in these patients in relation to the control group.

Raudino ${ }^{13}$ evaluated 25 women and 9 men patients, all with migraine without aura. They were submitted to the VEP-PR in $1.5 \mathrm{~Hz}$ frequency with electrodes placed in $\mathrm{Oz}$ and $\mathrm{Fz}$. Neither the latencies nor the P100 amplitudes differed from the control group.

Marsters et al. ${ }^{10}$ studied 64 migraine patients (41 with aura and 23 without aura) and submitted them to VEP-F and VEP-PR. The electrodes were placed in $\mathrm{Oz}$ and Fz. The VEP-F was obtained in $2 \mathrm{~Hz}$ frequency as the VEP-PR. In all cases, the stimulus source was $50 \mathrm{~cm}$ away of the patient. The frequency and the amplitude average of the quick activity $(14 \mathrm{~Hz})$ of the VEP base line were measured between 250 and 500 miliseconds (ms). In these measurements it was observed an increase in the quick activity between 250 and $500 \mathrm{~ms}$ and the VEP-F and VEP-PR in the migraine sufferers (with and without aura) in relation to the control group. After that, using mathematic calculation they obtained the quick wave coefficient in each studied group. With this criteria they could classify electrodiagnostically the control group, and the migraine sufferers with and without aura.

Diener et al. ${ }^{3}$ obtained the VEP-PR in 58 migraine patients with or without aura. The used frequency was of $1.56 \mathrm{~Hz}$ and electrodes were placed $2.5 \mathrm{~cm}$ above the inion, and the earth electrode in the left ear lobe. There was no variation in the latencies of the studied cases. Mortimer et al." studying 44 children suffering from migraine with and without aura and 50 without headache (control group) using the same technique obtained differences in the coefficient of the quick wave in the group without headache studied. The results obtained by Marsters et al. ${ }^{10}$ and Mortimer et al. ${ }^{11}$ were not confirmed by Peatifield ${ }^{12}$ and Van Dijck et al. ${ }^{15}$.

Mariani et al. ${ }^{9}$ obtained the VEP-PR in 20 migraine patients with visual aura (18 women and 2 men). Ten of these patients also presented migraine crisis without aura. The stimulus was done with the reversal pattern black and white, placed $1.5 \mathrm{~m}$ from the nasion. The active electrodes were placed in the occipital region, $5 \mathrm{~cm}$ above the inion $(\mathrm{Oz})$ and $5 \mathrm{~cm}$ on the side at right and left $(\mathrm{O} 2$ 
and 01) with the reference electrode in Fz. The frequency was of 1 flash/second until completing 128 stimulus. Analysing the results, they observed an increase of the P100 latency in migraine sufferers in relation to the control group. In the amplitudes, the obtained results were quite dispersed not only in migraine patients but also in the control group.

From the studies previously described, only those from Mariani et al. ${ }^{8,9}$ are useful in the comparison with our study since similar techniques were used to obtain the VEP-PR. In 1988, Mariani et al. ${ }^{8}$ submitted 22 patients with migraine without aura to the VEP-PR, without observing the changing in the P100 latencies in none of the patients. It is important to mention that the VEPPR used was only the black and white pattern. In 1990, the same authors obtained the VEP-PR black and white in 20 migraine sufferers with aura. However, $10(50 \%)$ from these patients also presented migraine without aura crisis. The VEP-PR showed an increase of the P100 wave latencies in all cases.

In our cases, from the 27 patients 9 presented normal P100 wave latencies in VEP-PR black and white, and red and green, corresponding to $33,33 \%$.

Mariani et al. ${ }^{9}$ attributed the compromise in the VEP-PR of the migraine patients to alterations in the monoamine neuromediators which occur even between the crisis. The hypothesis may also explain the increasing of the P100 latency in our cases, although this explanation remains as a conjecture, needing more data.

We have not an explanation to demonstrate why in 8 of our cases there was an increase in the P100 wave latency only in the VEP-PR red/green. Probably, the red and green stimulus is more sensitive. It will be necessary a larger number of VEP-PR exams using uniform techniques in patients with migraine so that, in future, we can obtain more concrete data to help to understand the pathophysiology of the migraine headache.

\section{REFERENCES}

1. Connolly JF, Gawel M, Clifford Rose F. Migraine patients exhibit abnormalities in the visual evoked potential. J Neurol Neurosurg Psychiatry 1982, 45: 464-467.

2. Dalla Volta G, Anzola GP. Are there objective critteria to follow up migranous patients ? A prospective study with termography and evoked potentials. Headache 1988, 28: 423-425.

3. Diener H-C, Scholz E, Dichgans J, Gerber W-D, Jack A, Bille A, Niederberger U. Central effects of drugs used in migraine prophylaxis evaluated by visual evoked potentials. Ann Neurol 1989, 25: 125-130.

4. Golla FL, Winter AL. Analysis of cerebral responses to flicker in patients complaining of episodic headache. Electroencephalogr Clin Neurophysiol 1959, 11: 539-549.

5. Headache Classification Committee of the International Headache Society. Classification and diagnostic criteria for headache disorders, cranial neuralgias and facial pain. Cephalalgia 1988, 8: 1-96.

6. Jasper HH. Report of the committee on methods of clinical examination in electroencephalography. Electroencephalogr. Clin Neurophysiol 1958, 10: 370-375.

7. Lehtonen JB. Visual evoked cortical potentials in man: studies on recording and stimulation technique, and findings in migraine patients. Thesis. University of Turku, 1972.

8. Mariani E, Moschini V, Pastorino G, Rizzi F, Severgnini A, Tiengo M. Pattern-reversal visual evoked potentials and EEG correlations in common migraine patients. Headache 1988, 28: 269-271.

9. Mariani E, Moschini V, Pastorino G, Rizzi F, Severgnini A, Tiengo M. Pattern reversal visual evoked potentials (VEP-PR) in migraine subjects with visual aura. Headache 1990, 30: 435-438.

10. Marsters JB, Good PA, Mortimer MJ. A diagnostic test for migraine using the visual evoked potential. Headache 1988, 28: 526-530.

11. Mortimer MJ, Good PA, Marsters JB, Addy DP. Visual evoked resposes in children with migraine: a diagnostic test. Lancet 1990, 335: 75-77.

12. Peatfield R. Visual evoked responses in children with migraine. Lancet 1990, 335: 480.

13. Raudino F. Visual evoked potential in patients with migraine. Headache 1988, 28: 531-533.

14. Richey ET, Kooi KA, Waggoner RW. Visually evoked responses in migraine. Electroencephalogr Clin Neurophysiol 1966, 21: 23-27.

15. Van Dijck JG, Dorresteijn M, Haan J, Ferrari MD. Visual evoked responses in children with migraine. Lancet 1991, 337: 517-518. 